\title{
Potentialities of Some Surface Characterization Techniques for the Development of Titanium Biomedical Alloys
}

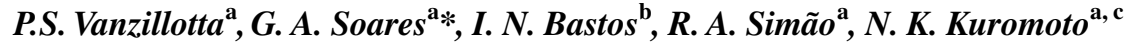 \\ ${ }^{\mathrm{a}}$ COPPE/UFRJ, P.O.Box 68505, Rio de Janeiro, 21945-970, RJ, Brazil \\ bIPRJ/UERJ, P.O. Box 97282, 28601-970 Nova Friburgo RJ, Brazil \\ 'Physics Department, UFPR, Curitiba PR, Brazil
}

Received: October 2, 2003; March 15, 2004

\begin{abstract}
Bone formation around a metallic implant is a complex process that involves micro- and nanometric interactions. Several surface treatments, including coatings were developed in order to obtain faster osseointegration. To understand the role of these surface treatments on bone formation it is necessary to choose adequate characterization techniques. Among them, we have selected electron microscopy, profilometry, atomic force microscopy (AFM) and X-ray photoelectron spectroscopy (XPS) to describe them briefly. Examples of the potentialities of these techniques on the characterization of titanium for biomedical applications were also presented and discussed. Unfortunately more than one technique is usually necessary to describe conveniently the topography (scanning electron microsocopy, profilometry and/or AFM) and the chemical state (XPS) of the external layer of the material surface. The employment of the techniques above described can be useful especially for the development of new materials or products.
\end{abstract}

Keywords: titanium, implant surface, characterization techniques

\section{Introduction}

Metallic implant materials have a significant impact in the biomaterials field, specially in applications requiring mechanical properties like mechanical strength and toughness. Among metallic materials, titanium and titanium alloys are considered the best choice for manufacturing permanent implants. The biocompatibility of titanium is due to the dense and well-adhered oxide layer, which is formed in contact with several environment, like air or water ${ }^{1}$. Commercially pure titanium and Ti-6Al-4V alloy are the two most common titanium-based implant biomaterials ${ }^{2}$, although some researchers discuss the potential citotoxicity associated to the vanadium element ${ }^{3}$.

The osseointegration concept was created by Branemark and since then, researchers all over the world have been trying to develop surfaces which can result into faster bone formation around a metallic implant. These surface treatments include mechanical blasting coupled or not, with acid etch ${ }^{4,5}$, bioactive coatings ${ }^{6-9}$ and, more recently, anodized surfaces ${ }^{10,11}$.

Besides implant design (macro scale), surface proper- ties in micro - and nanometric scale can affect bone formation. However, these properties (surface composition, surface energy and topography) are interrelated ${ }^{12}$ and consequently it is very difficult to determine how coatings and/or surface modifications affect - as an independent factor the final result. In the case of anodized titanium, the nature of oxide (thickness, porosity and crystallinity) seems to strongly affect in vivo performance, but the characterization of those nanometric layers is not trivial as it involves sophisticated and expensive techniques, like X-ray photoelectron spectroscopy (XPS), atomic force microscopy (AFM), Raman spectroscopy or ellipsometry ${ }^{12}$.

The biological behavior is determined by using in vitro (simulated body fluids or cell culture) and/or in vivo tests, usually employing rabbits or dogs as animal model ${ }^{13}$. The determination of the osseointegration percentage on in vivo tests is widely used by dentistry and implant producers, but this methodology is not highly sensitive to unequivocally correlate little surface differences to osseointegration data ${ }^{14}$. Cell culture is more appropriate to investigate material

*e-mail: gloria@ufrj.br 
behavior and the interaction between material surface and cells, although those results can not be directly extrapolated to clinical applications.

Among several techniques capable of investigating different aspects of the surface, we have chosen four to describe briefly. They are: electron microscopy, profilometry, atomic force microscopy (AFM) and X-ray photoelectron spectroscopy (XPS). Examples of the potentialities of these techniques on the characterization of titanium biomedical surfaces were also presented and discussed. The choice was made considering the capabilities of these techniques to measure properties related to biocompatibility, and in some cases, by the simplicity of sample preparation.

\section{Electron Microscopy}

Without considering optical microscopy, electron microscopy - specially scanning electron microscopy (SEM) - is the oldest and more popular technique employed in materials characterization. SEM is used as the first choice to examine a surface material, although sample preparation can introduce some artifacts. With the low-vacuum and environmental microscopes the sample preparation becomes even easier but, in Brazil, there is a limited number of such equipment.

SEM functions by focusing and scanning a relatively high-energy electron beam (usually $15-30 \mathrm{keV}$ ) on a speci- men. The main advantage of SEM is the use of the lowenergy secondary electrons (SE), resultant of the samplebeam interaction, to produce images with high focus depth. As only secondary electrons generated near the surface can escape and be detected, SEM can be considered a surface analysis method ${ }^{15}$ which generates beautiful topographic images. On the other hand, with the use of backscattered electrons (BSE) some topographic details are lost, but high contrast images can be obtained. BSE signal depends on the element atomic number in the analyzed region with brighter area corresponding to higher atomic number elements. This can be useful, for example, to identify contaminant particles on titanium surface. Figure 1a shows the topographic image of a titanium orthopedic plate coated with titanium by using plasma spray process in order to generate a rough topography, more suitable to osseointegration. Other option to create a rough topography consists in submit metallic surface to mechanical blasting, by using aluminum oxide or titanium oxide. In Fig. $1 \mathrm{~b}$ residual particles of alumina (darker) on a titanium sheet (brighter) were identified. These hard particles come from mechanical blasting with alumina ${ }^{4}$ and according to some researchers these residues can negatively affect osteoblast proliferation ${ }^{16}$.

Recently, some authors have also used SEM images to determine the osseointegration percentage, e.g., the contact length of bone-implant interface ${ }^{17-19}$. For this metallic im-

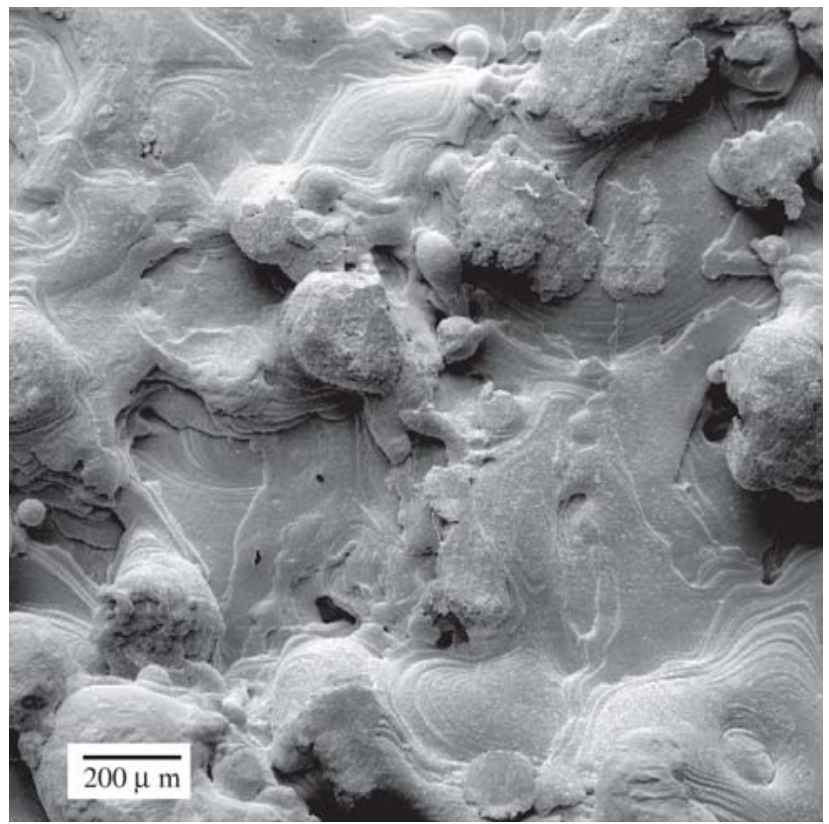

(a)

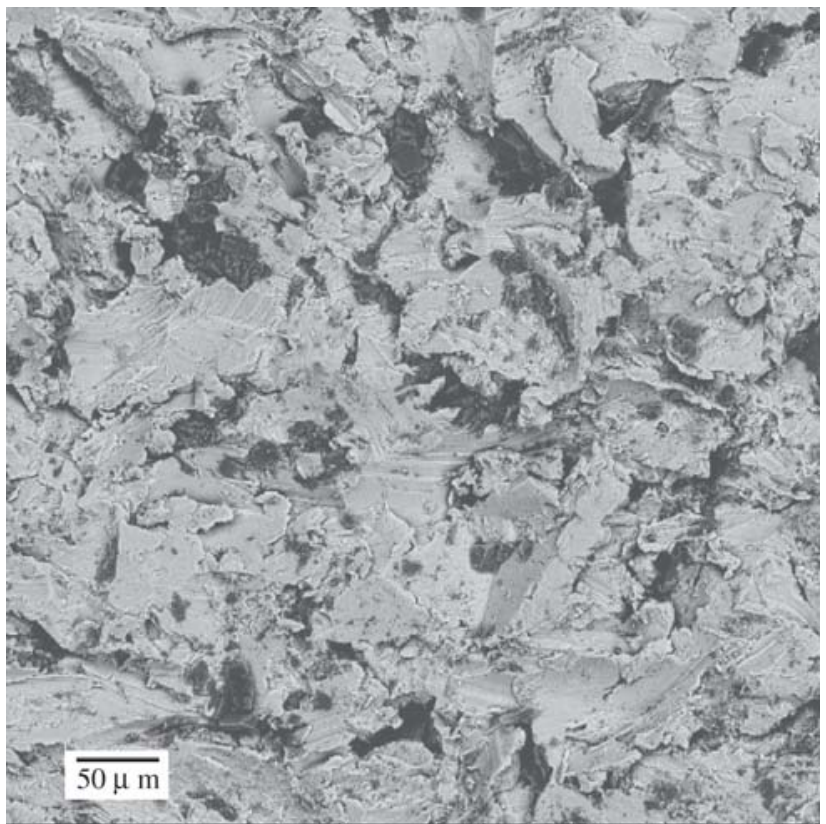

(b)

Figure 1. SEM images using different electron detectors: a) topographic image of a titanium orthopedic plate coated with titanium by plasma spray process. SE image; $(50 \times)$; b) residual particles of alumina (darker) on a titanium sheet (brighter) previously submitted to mechanical blasting with alumina. BSE image; $(200 \times)$. 
plants were inserted into rabbit's tibia, following approved protocols. After 2-3 months, the animals were sacrificed. Sections of each implant with surrounding bone tissue were removed, fixed, dehydrated and finally embedded in low viscosity resin. These samples can be examined through optical microscopy or more recently by using SEM ${ }^{19}$. The advantage of the use of SEM, instead of transmission optical microscopy, remains in the fact that, with SEM, the cut of very thin slices is not necessary. By using BSE image a good contrast can be achieved, as shown in Fig. 2, and consequently, those images can be easily processed by digital systems ${ }^{19}$.

Transmission electron microscopy (TEM) or scanningtransmission electron microscopy (STEM) can also be employed in surface characterization. As the preparation of cross-section samples is very laborious, not so much data concerning titanium surface investigation is available in current literature.

Usually electron microscopy is associated with energy dispersive spectrometer (EDS) which provides qualitative or semi-quantitative information concerning elements present in a such region. The collision of the electron beam with sample surface removes some electrons from their positions which is followed by electron transition. Consequently, a X-ray emission with characteristic energy related to the transition type occurs. After the collection by specific sensor and the processing of the signal, it is transformed into EDS spectrum. This information is very important for several researches, but this type of analysis is not actually considered a surface technique because X-ray signal is collected from depths up to $1 \mu \mathrm{m}$, depending on the voltage and the electron beam diameter utilized ${ }^{20}$.

While SEM qualitatively describes the surface topography, it does not provide the quantitative values of the surfaces. Therefore, profilometry seems to be more convenient to quantify topographical parameters.

\section{Profilometry}

In many applications, topography represents the main external features of a surface. A relatively new and developing field of application of three-dimensional analysis is that of bioengineering, where the surface texture can be very important. Besides its clear influence on mechanical stress distribution in the interface implant-bone, the texture is expected to affect the protein adhesion, the orientation of bone growth and consequently, the clinical performance.

The real surface differs from the nominal one due to the presence of surface texture, flaws and errors of form ${ }^{21}$. Indeed, these components are linearly overlapped. In this sense, the components of real surface may be classified as:

- Roughness - the finer irregularities of the surface texture that usually result from the inherent action of the

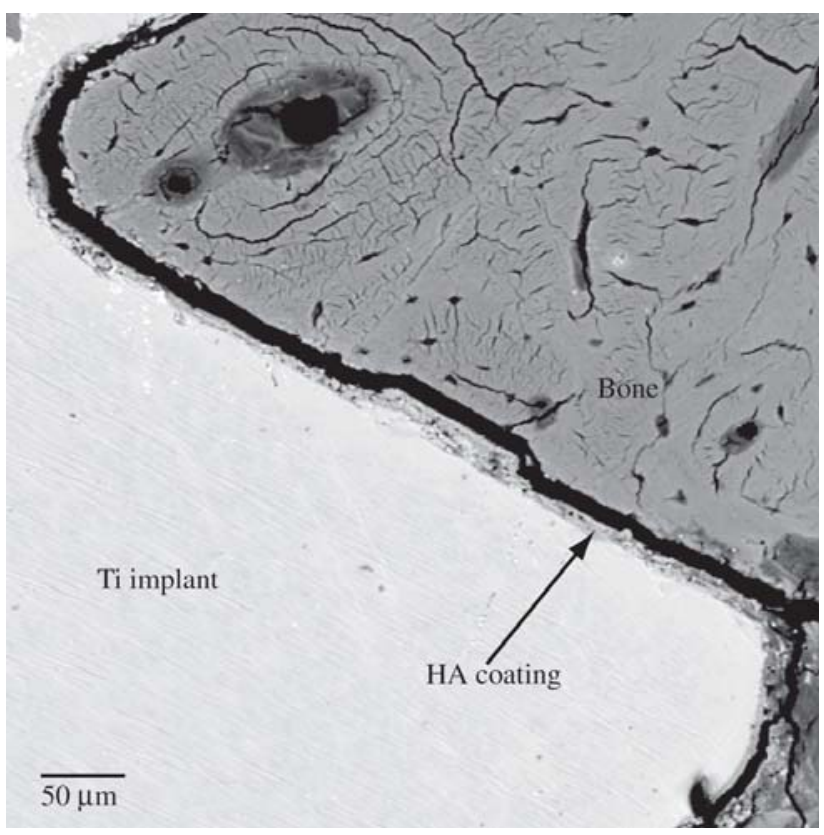

Figure 2. BSE image of the bone-implant interface after in vivo test; $(100 \times)$.

production process or material condition;

- Waviness - the more widely spaced component of the surface. Vibrations, workpiece or machine deflections are the common causes for this component;

- Lay - the predominant direction of the surface pattern, normally determined by the production method used.

The main procedure to discriminate these components is the choice of adequate cutoff. The cutoff separates roughness and waviness by using proper spatial lengths. The cutoff is expressed in $\mathrm{mm}$ and standard values are available elsewhere ${ }^{22}$. In biomaterial field, roughness gained more attention as its spatial scales are closer to the chemical, biological and mechanical process scales that take place on the metallic surface.

Methods of measurements can be classified as contact or non-contact methods, and as three-dimensional (area), $3 \mathrm{D}$, or two-dimensional (profile), 2D procedures. The contact equipment uses a stylus that plows through the surface of workpiece. On soft materials, the stylus may produce a visible mark as it is being used. Such mark does not necessarily mean that the measurement is incorrect. In these cases, it may be desirable to make supplementary measurement with a non-contact instrument to ascertain that the penetration into the material is small compared to the irregularities being measured ${ }^{23}$. In general, the equipment for the measurement of surface texture encompass full profiling instruments, instruments with parameters and limited profile capability, and instruments with parameters only. Therefore, 
whenever this non-contact measurement is available, this has to be the chosen technique to evaluate the texture parameters. Otherwise, the non-contact profilometry isn't available, special care should be taken by the users, since this procedure is influenced by space dimensions and plastic deformation. Besides, the statistical descriptors obtained from profilometry have complex physical meanings not being possible to directly associate them to different experimental techniques. As the plastic deformation produced by the stylus is dependant on surface hardness and the actual local stress one preliminary guide should be the surface hardness, but, as yet, the authors of this paper do not know of any published standards that can be based upon. Thus, the contact profilometry is currently used to evaluate the texture of titanium samples as shown in the literature works, in spite of visible deformation on titanium surface.

The traditional parameter used to evaluate a surface is a roughness average, $R_{a}$. The $R_{a}$ parameter is the arithmetic average of the absolute values of the profile height deviation recorded within the evaluation length and measured from the mean line.

This is a 2D parameter and even the simplest equipment provides this parameter. Although the widespread use of $\mathrm{R}_{\mathrm{a}}$, it is not a parameter of merit, and frequently its value does not produce good correlation with the expected biologic behavior. In this sense, hip joint surfaces with similar $\mathrm{R}_{\mathrm{a}}$ may have different behavior in surgical success ${ }^{21,15}$. This situation points out the necessity of other parameters to express correctly the surface nature. Indeed, there are many $2 \mathrm{D}$ and $3 \mathrm{D}$ parameters to evaluate quantitatively the surface, but only a 3D facilities provides information related to all surface, since the real surface of implants are 3D.

The full profiling instrument allows a qualitatively vision of surface and also gives numerical 3D parameters. As an example, Fig. 3 shows a 3D plot of etched titanium alloy after alkali treatment with $\mathrm{NaOH}$ aqueous solution at $130^{\circ} \mathrm{C}$ for $1 \mathrm{~h}$ and subsequent heat treatment at $600{ }^{\circ} \mathrm{C}$ for $1 \mathrm{~h}^{24}$.

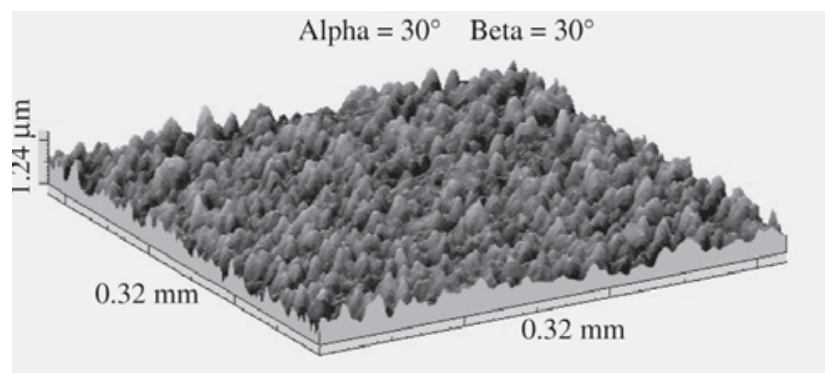

Figure 3. Three dimensional plot of titanium surface after alkali treatment with $\mathrm{NaOH}$ aqueous solution at $130{ }^{\circ} \mathrm{C}$ for $1 \mathrm{~h}$ and subsequent heat treatment at $600{ }^{\circ} \mathrm{C}$ for $1 \mathrm{~h}$ by contact profilometry technique.
This procedure is normally used before soaking Ti implant in simulated body fluid to nucleate calcium phosphate ${ }^{24}$. Therefore, the osseointegration process is improved.

When full profiling instruments are used, the $\mathrm{R}_{\mathrm{a}}$ parameters can be changed to $S_{a}$, which corresponds to all surface, not only to a single profile. In the present case, where Ti was ground with emery paper and subsequently etched with $\mathrm{NaOH}$, it is possible to note that the attack was sufficient to remove the lay left by abrasives. The $S_{a}$ value is $0.134 \mu \mathrm{m}$ for this surface. Table 1 shows some $3 \mathrm{D}$ parameters that can be useful to describe the surface of implants.

The evaluation of smoothness of hip prosthesis surfaces requires to be measured down to nanometer level in order to monitor wear and pit distribution, and 3D profilometry are suitable ${ }^{21}$. Another process that occurs in spatial scale smaller than the current technique cannot be highly correlated with the evaluated surface parameters since the dimensions are not similar. The stylus itself limits the minimum size of the irregularities that can be measured. The typical radii of profilometry ranging between $1-10 \mu \mathrm{m}$, and its space resolution is about $1 \mu \mathrm{m}$. The atomic force microscopy has a radius of approximately $100 \mathrm{~nm}$, and spatial resolution of $5 \mathrm{~nm}$. These characteristics naturally select the related interface phenomena. The influence of some factors like binding proteins to the surface, ionic leakage and cellular adhesion will result only in good correlation with texture if the geometric scales are similar. For example, the cell adhesion is better when the peaks are not too high and the valleys are not too deep ${ }^{25}$. Therefore, to study these specific effects, a technique with higher spatial resolution can be more adequate. The AFM - atomic force microscopy is the technique suitable to quantify topography when spatial scales are small.

\section{AFM - Atomic Force Microscopy}

Among several probe microscopies, AFM - developed

Table 1. Some three-dimension parameters used to describe surfaces. The example is referred to the titanium sheet presented in Fig. 3.

\begin{tabular}{ccc}
\hline Abreviation & Meaning & Ti sheet \\
\hline Sa & $\begin{array}{c}\text { Arithmetic mean of the absolute } \\
\text { values of the surface } \\
\text { Root mean square value } \\
\text { of the surface }\end{array}$ & $0.134 \mu \mathrm{m}$ \\
Ssk & $\begin{array}{c}\text { Skewness, measure of the } \\
\text { symmetry of the surface } \\
\text { Kurtosis, measure of the } \\
\text { Sku }\end{array}$ & $0.221 \mu \mathrm{m}$ \\
sharpness of the surface \\
Sz & $\begin{array}{c}\text { Mean value of the 5 deepest } \\
\text { valleys and 5 highest peaks }\end{array}$ & $1.58 \mu \mathrm{m}$ \\
\hline
\end{tabular}


around the 90's - is preferred due to its versatility: the sample may not be a conductor and it may be examined even in liquid media. The AFM principle is similar to the contact profilometry but works with nanometric tip and a very sensitive system resulting in surface investigation in nanometric scale.

Beyond being merely a tool for measuring surface topography, AFM has made significant contributions to biomaterials research in areas dealing with structure, properties, dynamics and manipulation ${ }^{26}$. Interface phenomena like protein adsorption, conformational changes and subsequent interaction with cellular components could not be observed directly until the advent of the atomic force microscopy ${ }^{27}$. As it was told before, these mechanisms may explain why one surface treatment can exhibit a performance superior to another. Force detection techniques allow the determination of cell adhesion on metallic surfaces, contributing to molecular level studies of individual receptorligand binding events ${ }^{27}$.

AFM images require posterior processing and its analysis is not trivial as several parameters (i.e. special tip configuration) may affect final result. The surface of the anodized titanium sheet was investigated by using AFM. The material investigated consists of commercially pure titanium sheets $(20 \times 10) \mathrm{mm}^{2}$ with $0.9 \mathrm{~mm}$ of thickness. To attain this effect, the surface of the sample was carefully ground with silicon carbide and polished with alumina plus oxalic acid. After that, half of the sample was coated with enamel to avoid that this region was etched during the electrochemical treatment. Anodizing process was carried out at room temperature (RT) using $\mathrm{H}_{3} \mathrm{PO}_{4}$ solution (8\%), a platinum counter electrode and applied voltage of $20 \mathrm{~V}$ for $10 \mathrm{~min}$, resulting in a blue color film ${ }^{28}$. After anodic etching two different regions could be clearly distinguished on the sample: one containing only polished titanium (with a very thin oxide layer) and the other containing the oxide film electrochemically produced. AFM measurements were performed at RT in air. We used conventionally available $\mathrm{Si}_{3} \mathrm{~N}_{4}$ tips, spring constant of the cantilever equal $0.6 \mathrm{~N} / \mathrm{m}$ and imaged the surface in contact mode using a tripot $100 \mu \mathrm{m}$ scanner.

Figure 4a shows a three dimension (3D) view $(15 \mu \mathrm{m} \times$ $15 \mu \mathrm{m} \times 100 \mathrm{~nm}$ ) of the titanium surface and probe the two regions of the sample. The thickness of the anodized layer was measured by using data obtained from line profiles on the interfacial region, like that showed in Fig. 4b. The medium value was around $30 \mathrm{~nm}$ which is less than data obtained by other authors ${ }^{29,30}$. Titanium surface with natural oxide film and anodized film has the appearance illustrated in Fig. $4 c$ and 4d, respectively. Figure $4 c$ shows the nontreated titanium surface exhibiting a very thin oxide layer consisting in nanometric grain size oxide. In the anodized film region, an increase in roughness and in grain size of the oxide layer was observed (Fig. 4d). This result is in good agreement with Bearinger et al. ${ }^{31}$ who showed that the oxide growth depends on the environment conditions. In the open air, adsorption and nucleation events occur immediately, thereby rapidly creating a few monolayers of titanium oxide on the titanium substrate; upon immersion in anodized medium the oxide continues to grow and coalesce.

Unfortunately, neither AFM nor profilometry gives chemical information of the surface, so these techniques must be coupled with chemical investigation in nanoscale, with the use of, for example, the X-ray photoelectron spectroscopy.

\section{X-ray Photoelectron Spectroscopy - XPS}

X-ray photoelectron spectroscopy (XPS), also called elemental spectroscopy for chemical analysis (ESCA) is a very important technique to identify chemical species on materials surface. This technique is not very popular due to its high equipment cost and because the spectra interpretation is not trivial. The photoelectric effect was described by Einstein in 1905, but the use of XPS for materials characterization started only in the 80 's ${ }^{15}$ and data available are not yet sufficient to identify all spectra unequivocally. The XPS principle is quite similar to the EDS principle, but instead of an electron beam, XPS uses a monochromatic lowenergy X-ray beam. The interaction between the incident beam and the atoms of the material causes the emission of a core level electron. The XPS detects the kinetic energy of electrons which provides information about the nature and environment of the atom from which it came ${ }^{15}$. Among the advantages of using XPS for biomaterials characterization, the possibility to analyze samples without particular specimen preparation may be pointed out. The disadvantages are related to the need of vacuum compatibility, the possibility of sample damage and the difficult of equipment availability.

Figure 5 shows the XPS spectrum of a titanium sheet anodized with $\mathrm{H}_{3} \mathrm{PO}_{4}(8 \%)$ solution at $20 \mathrm{~V}$ for $10 \mathrm{~min}^{11}$. The aim of this surface treatment is to develop a titanium oxide layer as several recent researches consider this surface suitable to accelerate osseointegration ${ }^{10,12,29}$. It is not clear how this kind of surface interacts with biological media, but we have speculated whether phosphorus ions could be incorporated to oxide layer helping the cascade of events that culminate in mature bone. Although this latter information is not yet confirmed, by XPS analysis we could identify the presence of phosphorus with kinetic energy compatible with phosphate group ${ }^{32}$. XPS spectrum can be quantified but error is estimated in around $10 \%$.

XPS technique has also been used on investigations concerning in vitro behavior of synthetic materials. Since Kokubo's results proved that under some conditions it is possible to develop an apatite layer on a synthetic material and that this apatite formation is a good indication of in 


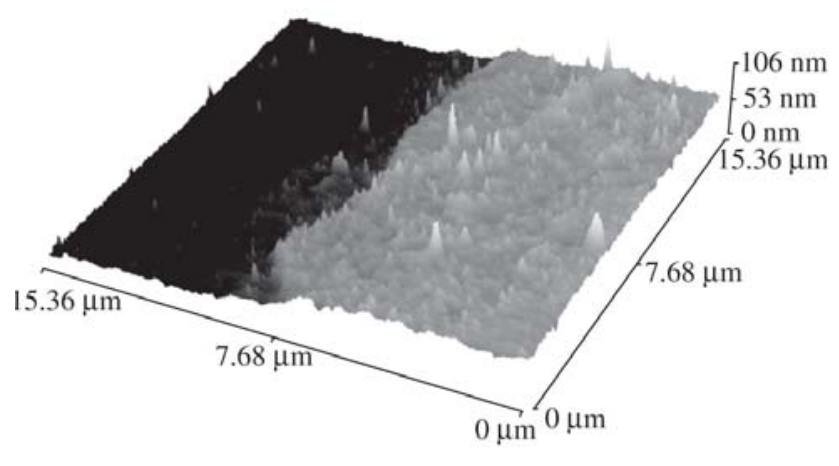

(a)

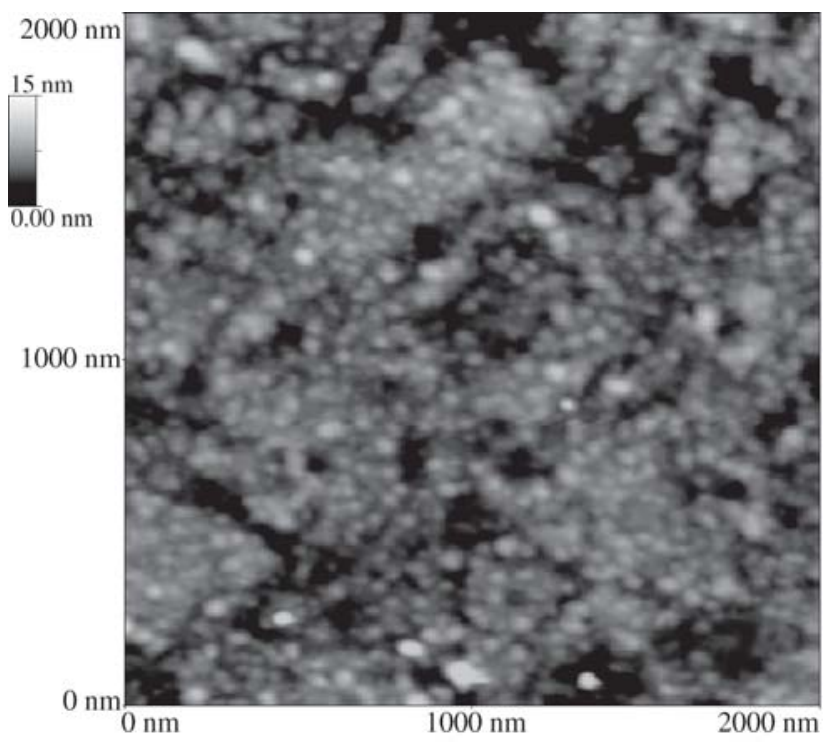

(c)

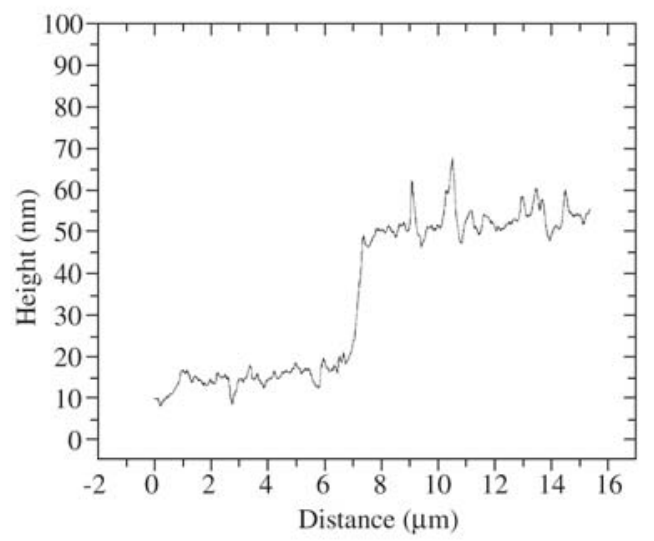

(b)

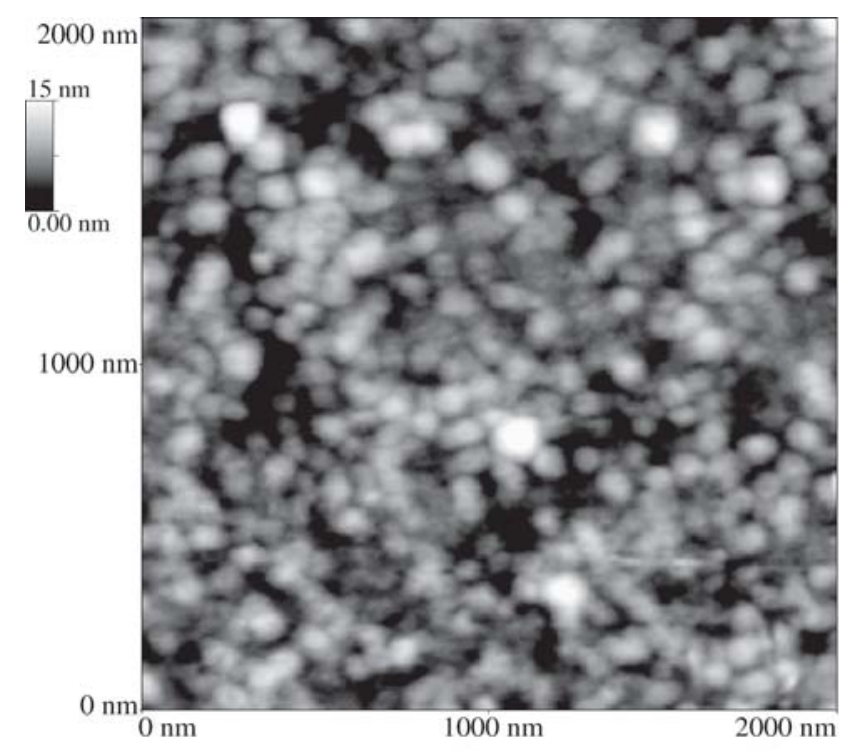

(d)

Figure 4. Anodized film produced by electrolytic etch on the half surface of commercially pure titanium sheet: a) 3D view. Darker region corresponds to polished titanium surface; b) Line profile on interfacial region from Fig. $4 \mathrm{a}$; c) Image $(2 \mu \mathrm{m} \times 2 \mu \mathrm{m})$ of natural oxide film; d) Image $(2 \mu \mathrm{m} \times 2 \mu \mathrm{m})$ of anodized oxide film.

vivo success ${ }^{33}$, these in vitro tests became very popular. This kind of in vitro test, also called "bioactivity test" consists in soaking a synthetic material in a simulated body fluid SBF (usually inorganic acellular solutions) for some time up to several days or months. The material can be consider bioactive if on its surface appears an apatite layer precipitated from ions present on SBF. By XPS investigation the apatite formation can be followed and precisely identified $^{32,34}$. Figure 6 shows the differences on the $\mathrm{O} 1 \mathrm{~s}$ region of a titanium anodized surface before and after 7 days ex- position to a $\mathrm{SBF}^{11}$. The Ti anodized surface exhibits oxygen with energy corresponding to a titanium oxide, $\mathrm{TiO}_{2}$. After SBF soaking, the energy of O 1s changed with this value compatible with the oxygen in the phosphate radical. After this time the total calcium content reached 15.5 at. $\%$ and the content of $P$ increased from $3.5(t=0)$ to 9.6 at.\% $(\mathrm{t}=7$ days $)$, resulting in a $\mathrm{Ca} / \mathrm{P}$ ratio $(1.61 \pm 0.16)$ compatible with an hydroxyapatite ${ }^{32}$.

Several other techniques may be employed in biomedical surface characterization. Surface energy is very impor- 
tant as it can alter protein configuration and cell attachment and can be determined by contact-angle measurements. Unfortunately, no direct correlation between surface energy parameters and cell proliferation has already been established. Other sophisticated techniques involving interactions with electrons (Auger electron spectroscopy - AES, electron energy loss spectroscopy EELS), ions (secondary ion mass spectroscopy - SIMS, ion scattering spectroscopy - ISS) or neutrons (neutron scattering) may be useful. For example, static SIMS is more adequate to identify a particular protein configuration than $\mathrm{XPS}^{12}$, although the use of these techniques is not trivial. Consequently, a more fundamental research is necessary to understand the processes occurring at biological interfaces, thus clarifying the role of materials surface on bone formation process.

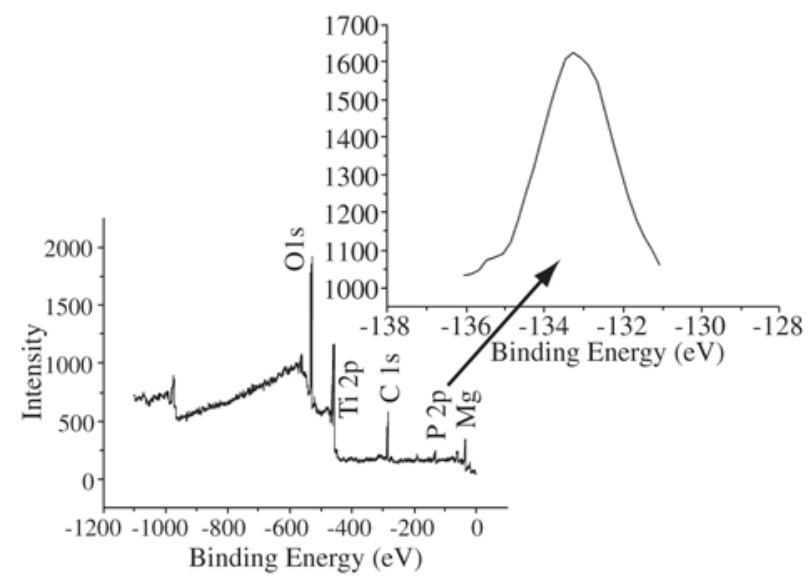

Figure 5. XPS general spectrum of a titanium sheet anodized with $\mathrm{H}_{3} \mathrm{PO}_{4}$ solution. On detail the $\mathrm{P} 1 \mathrm{p}$ region is shown.

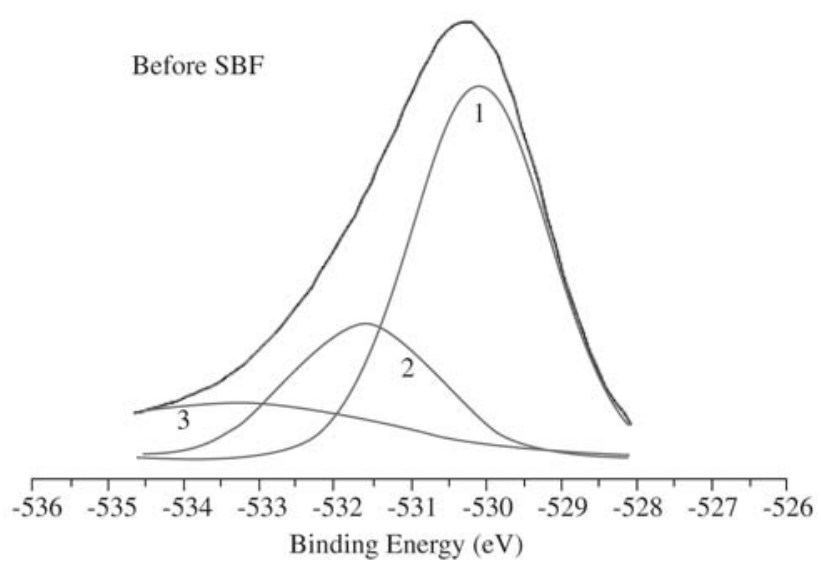

\section{Conclusions}

The characterization of materials surface is very important as initial in vivo response is highly dependent on surface properties. Among the techniques herein discussed, scanning electron microscopy (SEM), profilometry and atomic force microscopy (AFM) are very adequate to investigate materials topography in different scale levels. In order to chemically characterize the outer layers of titanium/titanium alloys surface X-ray photoelectron spectrometry (XPS) is the most appropriate technique. Summarizing, the four techniques presented have potentialities to characterize the titanium biomedical alloys in order to improve their subsequent in vivo performance, but more than one technique is necessary to describe conveniently the material surface.

\section{Acknowledgements}

The authors would like to acknowledge the support of CAPES, CNPq, FAPERJ and FUJB. The XPS spectra were obtained in the NUCAT Lab. at PEQ/COPPE/UFRJ. This research is part of the Molecular and Interfaces Nanotechnology Research Network (RENAMI) supported by CNPq.

\section{References}

1. Diebold, U., The Surface Science of Titanium Dioxide, Surf. Sci. Reports, v. 48, p. 53-229, 2003.

2. Steinemann, S.G., Periodontology, v. 17, p. 7-20, 1998.

3. Froes, F.H.; Caplan, I.L., Proceedings of the Titanium92, San Diego, California, v. 3, p. 2705, 1992.

4. Diniz, M.G.; Soares, G.A.; Coelho, M.J.; Fernandes, M.H., J. Mater. Science: Mater. in Medicine, v. 13, p. 421-432, 2002.

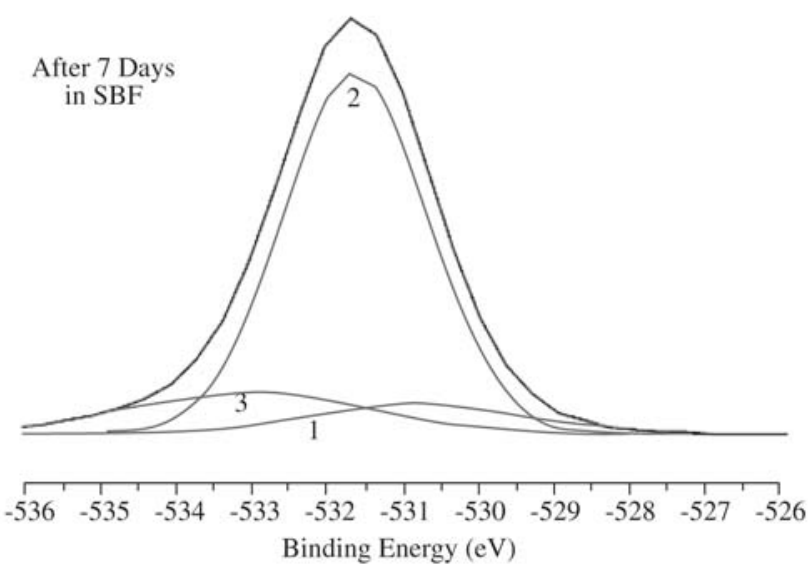

Figure 6. Anodized titanium sheet before and after immersion for 7 days into SBF around. XPS spectra around $\mathrm{O}_{1 \mathrm{~s}}$ region. 1) $\mathrm{O}^{2-}$;2) $\mathrm{OH}^{-}$ or $\left.\mathrm{PO}_{4}{ }^{3-} ; 3\right)$ adsorbed water. 
5. Wennerberg, A.; Albrektsson, T.; Andersson, B., The Intern. JOMI, v. 11, n.1, p. 38, 1996.

6. De Groot K.; Wolke J.C.K.; Jansen J.A., J. of Oral Implantology, p. 232-234, 1994.

7. Shi, J.; Ding, C.; Wu, Y., Surface and Coatings Tech., v. 137, p. 97-103, 2001

8. Kokubo T.; Miyaji F.; Min-Kim H.; Nakamura T., J. of the American Ceramic Society, v. 79, n. 4, p. 1127-29, 1996.

9. Sena, L.A.; Andrade, M.C.; Rossi, A.M.; Soares, G.A., J. Biomed. Mater. Res, v. 60, p. 1-7, 2002

10. Sul, Y.T.; Johansson, C.B.; Petronis, S.; Kroser, A.; Jeong, Y.; Wennerberg, A.; Albrektsson, T., Biomaterials, v. 23, p. 491-501, 2002.

11. De Sena, L.A.; Rocha, N.C.C.; Andrade, M.C.; Soares, G.A. Surface and Coatings Technology, v. 166, p. 254258, 2003.

12. Jones, F.H., Surface Science Reports, v. 42, p. 75-205, 2001.

13. Black, J., Biological Performance of Materials: Fundamentals of Biocompatibility, Marcel Dekker Inc., New York, p. 285-329, 1992.

14. Almeida, J.M.V., M.Sc. Thesis, COPPE/UFRJ, Brazil, 2003.

15. Ratner, B.D.; Hoffman, A.S.; Schoen, F.J.; Lemons, J.E., Biomaterials Science: An Introduction to Materials in Medicine, Academic Press, California, USA, p. 23-28, p. 447-449, 1996.

16. Prado da Silva, M.H.; Soares, G.A.; Elias, C.N.; Best, S.M.; Gibson, I.R.; DiSilvio, L.; Dalby, M.J., J. of Mater Sci.: Mater in Medicine, v. 13, p. 511-519, 2003.

17. Vidigal Jr., G.M.; Sader, M.S.; Soares, G.A., Anais do XVIII CSBMM, Águas de Lindóia, SP, Brazil, p. 09-10, outubro/2001

18. Brogniez, V.; D’Hoore, W.; Grégoire, V.; Munting, E., The Intern. JOMI, v. 15, n. 4, p. 511-518, 2000.

19. Almeida, C.C., M.Sc. Thesis, COPPE/UFRJ, Brazil, 2002.
20. Kestembach, H-J.; Botta F.; W.J., Microscopia Eletrônica de Transmissão e Varredura, Édile Serviços Gráficos e Editora Ltda., SP., Brazil, p. 104, 1994.

21. Stout, K.J.; Blunt, L.; Int. J. Mach. Tools Manufact., v. 35, p. 219-229, 1995.

22. Surface Texture, ASME B46.1-1995 Standard, New York, USA, 1996.

23. Chappard, D.; Degasne, I.; Huré, G.; Legrand, E.; Audran, M.; Baslé, M.F. Biomaterials, v. 24, p.13991407, 2003.

24. Pinto, V.B.B., M.Sc. Thesis, COPPE/UFRJ, Brazil, 2003.

25. Bigerelle, M.; Anselme, K.; Dufresne, E.; Hardouin, P.; Iost, A. Biomolecular Engineering, v. 19, p. 79-83, 2002.

26. Jandt, K.D., Surface Science, v. 491, n. 3, p. 303-332, 2001.

27. Siedlecki, C.A.; Marchant, R.E., Biomaterials, v. 19, p. 441-454, 1998.

28. Kuromoto, N.K.; Sena, L.A.; Simão, R.A.; Soares, G.A., Anais do XIX CSBMM, Caxambu, MG, Brazil, 2003.

29. Velten, D.; Biehl, V.; Aubertin, F.; Valeske, B.; Possart, W.; Breme, J., J. of Biomedical Mater.Research, v. 59, n. 1, p. 18-28, 2002.

30. Cigada, A.; Cabrini, M.; Pedeferri, P., J. of Mater. Science: Materials in Medicine, v. 3, p. 408-412, 1992.

31. Bearinger, J.B.; Orme, C.A.; Gilbert, J.L., Surface Science, v. 491, p. 370-387, 2001.

32. Takadama, H.; Kim, H-M.; Kokubo, T.; Nakamura, T., Surface and Tech. of Advanced Materials, v. 2, p. 389396, 2001.

33. Kokubo, T.; Kim, H.M.; Kawashita, M.; Nakamura, T., in: Bone Engineering, ed. By J.E. Davies, Canada, p. 190-194, 2000.

34. Casaletto, M.P.; Ingo, G.M.; Kaciulis, S.; Mattogno, G.; Pandolfi, L.; Scavia, G.; Applied Surface Science, v. 172, p. 167-177, 2001. 